\title{
Elderberry and Elderflower (Sambucus spp.): A Cultivation Guide for Florida'
}

\author{
David Jarnagin, Ali Sarkhosh, Juanita Popenoe, Steve Sargent, and Kevin Athearn²
}

Elderberry, Sambucus spp., has long been cultivated or collected from the wild by humans for both food and medicine. Europeans have used the flowers and fruit of Sambucus nigra for thousands of years, while Native Americans and European immigrants used Sambucus nigra ssp. canadensis, native to the New World (Figure 1).
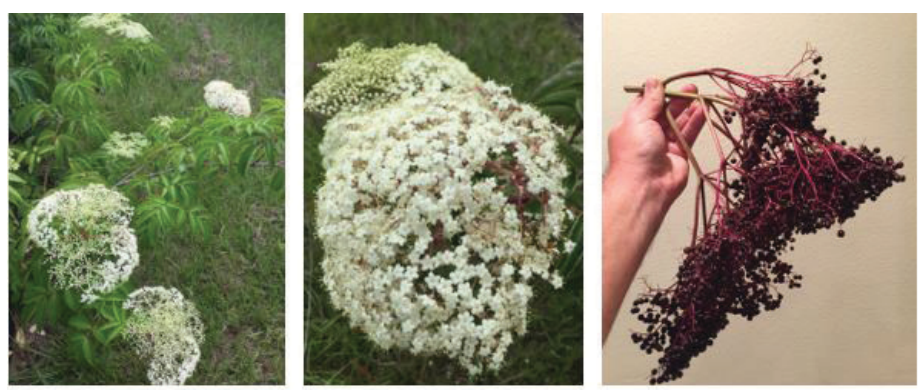

Figure 1. Elderberry and elderflower cymes.

Credits: Hyldemoer + Co., Florida

The purpose of this paper is to provide information on growing American elderberry in Florida as an alternative crop for commercial growers as well as homeowners. Although elderberry has been historically grown at commercial scale in some world regions, especially throughout Europe, in the New World it has not found meaningful commercial acceptance until recently. It has typically been more of a small-scale or backyard crop in the United States, possibly because of the challenges of harvest and postharvest processing and reports of the toxic nature of parts of the plant.
Pushes for commercial cultivation were initiated in various regions of North America in the 1920s and again in the 1960s, but the most recent iteration of commercial cultivation over the last 10 to 15 years has outpaced the previous attempts considerably. The high levels of antioxidants and health benefits of the fruit have created new demand for the fruit and flowers, and this new demand may provide an alternative crop opportunity for Florida growers with many value-added possibilities. A native species grows wild throughout Florida, indicating that this may be a perennial crop that can be sustainably grown on marginal land. However, the native Florida plants have many drawbacks compared to the more commonly cultivated forms originating from farther north, and these drawbacks are an important consideration for proper establishment on a commercial scale. The fruit and flowers of the elder are used for wine, preserves, tinctures, teas, brewing and distilled spirits, and dyes for both food and textiles. The anthocyanins in the fruit have been found to have higher antioxidant properties than vitamin $\mathrm{E}$ or $\mathrm{C}$ as well as antiviral activity owing to a variety of phytochemical compounds. Different growing conditions may cause more variability in fruit and flower compositional quality than varietal differences, making cultivation techniques and environment important factors.

1. This document is HS1390, one of a series of the Horticultural Sciences Department, UF/IFAS Extension. Original publication date October 2020. Visit the EDIS website at https://edis.ifas.ufl.edu for the currently supported version of this publication.

2. David Jarnagin, Hyldemoer + Co.; Ali Sarkhosh, assistant professor and Extension specialist, Horticultural Sciences Department; Juanita Popenoe, multicounty commercial fruit production agent IV, UF/IFAS Extension Lake County; Steven Sargent, professor and postharvest Extension specialist, Horticultural Sciences Department; Kevin Athearn, regional Extension specialized agent, UF/IFAS North Florida Research and Education CenterSuwannee Valley; UF/IFAS Extension, Gainesville, FL 32611.

The Institute of Food and Agricultural Sciences (IFAS) is an Equal Opportunity Institution authorized to provide research, educational information and other services

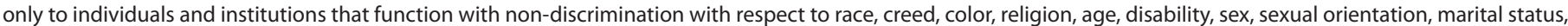

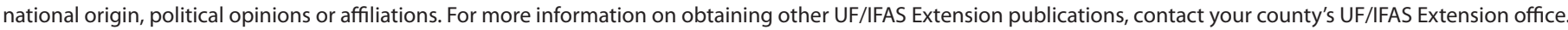
U.S. Department of Agriculture, UF/IFAS Extension Service, University of Florida, IFAS, Florida A \& M University Cooperative Extension Program, and Boards of County Commissioners Cooperating. Nick T. Place, dean for UF/IFAS Extension. 
Other Sambucus species have been used for many purposes and may provide additional potential for cultivation in Florida, whether as a commercial crop or for genetic diversity for breeding purposes. Information about markets and budgeting can be found in another EDIS publication, Elderberry and Elderflower (Sambucus spp.): Markets, Establishment Costs, and Potential Returns.

\section{Differentiating Sambucus Species}

The specific type of Sambucus nigra ssp. canadensis native to Florida was at one time classified as a separate species, S. simpsonii, but is currently grouped with the canadensis subspecies. There are significant differences to note for commercial production between native Florida phenotypes and American Sambucus found farther north. As has been found in many areas of the country, the European species, S. nigra, does not thrive long term in Florida and also appears to have a higher reproductive chill-hour requirement than occurs in the South.

Some differences between species are visually obvious, as shown by variation in leaflet size and configuration of three species below (Figure 2). Other important differences are discussed later in this document. This paper discusses cultivation of American Sambucus species and varieties, though species from other parts of the world that have not previously been evaluated may also hold potential.
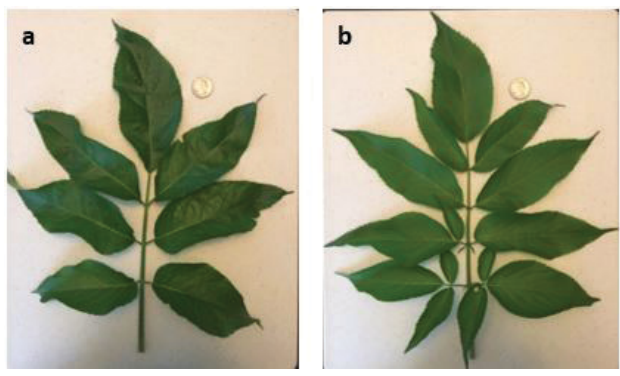

c

Figure 2. Mature leaves of maximum size: (a) S. nigra (most often having 7 leaflets with a maximum of 9), (b) S. canadensis, (most often having 9 or more leaflets and ranging from 7 to 11 or more), and (c) $S$. simpsonii (most often having 9 or more leaflets and ranging from 7 to 11 or more).

Credits: Hyldemoer + Co., Florida

Another form of Sambucus, previously known as S. mexicana, has also been reported in Florida. This form does not appear to have commercial fruit or flower production value (see https://edis.ifas.ufl.edu/st580). Sambucus varies widely across North America despite the recent and considerable reduction in number of named species as compared to older taxonomy; S. simpsonii has been largely removed as a separate species or subspecies, and $S$. mexicana is most often replaced with either the $S$. nigra ssp. canadensis or $S$. nigra ssp. cerulea species names, depending on geography, further confusing the identity of these conspicuously different plants.

The American elderberry's growth habit varies from shrub to tree form throughout the continent. It is typically propagated by cuttings, and selections from the wild have historically been the norm. Selected phenotypes may vary considerably from plant to plant even within a single wild stand, and propagation from these wild stands may cause confusion when the resulting mix of plants is marketed as a "variety" without proper trialing. Historic cultivars, home selections, cultivars from a few, very limited breeding programs, and nursery-propagated cultivars are all available. All of these sources may become mixed over time, and though elderberry has a long tradition of cultivation in this country, it has typically been grown only on a small scale with relatively little documentation. This circumstance may also contribute to misidentification as hardwood cuttings or other propagation materials are handed down from one grower to the next. Proper documentation and trialing of varieties grown at commercial scale in Florida will be vital to the future success of the crop here.

\section{Crop Management Propagation}

Elderberry can be propagated from hardwood cuttings, softwood cuttings, and seed. Propagation from seed is not preferable for commercial elderberry cultivation because of the variation that would be produced in the seedling populations. Sambucus is relatively difficult to start from seed in any case, with a cold-stratification requirement and a long term to germination under warm conditions following the overwintering requirement. Propagation from hardwood cuttings is most often recommended because of its relative ease and low cost for large-quantity propagation (Figure 3).

As many as $8-10$ hardwood cuttings can be taken from the typical primocane in late winter (January to March) before bud break with two nodes each. The cuttings should be taken from canes that were grown in the previous season. Dipping the basal end of the cuttings in $0.1 \%$ IBA (Indole-3-butyric acid) may increase rooting efficiency; however, rooting without IBA also works well. Depending on the time of year cuttings are started, they may be placed directly in ground under drip irrigation or put in starter pots with rooting medium, with the nodes at the bottom one and a half to two inches under the surface of the medium. Roots will grow over a period of approximately 4-6 weeks, depending on temperature and moisture levels. 
Planting directly in ground is preferable to potting, but if potted, keep the cuttings warm and moist. The cuttings should not be allowed to dry out or be kept too wet. Potted cuttings should be well-rooted within six to eight weeks and can be transplanted into the field after the last frost. If needed, the rooted cuttings can be transplanted into 6-inch pots. Elderberry is a very fast-growing plant in favorable conditions, and root-binding is a major concern if grown in pots for more than a few months. The potted transplants grown successfully for one season establish well in the next season, or they may be cut into pieces of main root, stolon, and crown sections along with hardwood cuttings. This method results in one potted plant yielding several (sometimes 20 or more) new plants for propagation in ground next season.
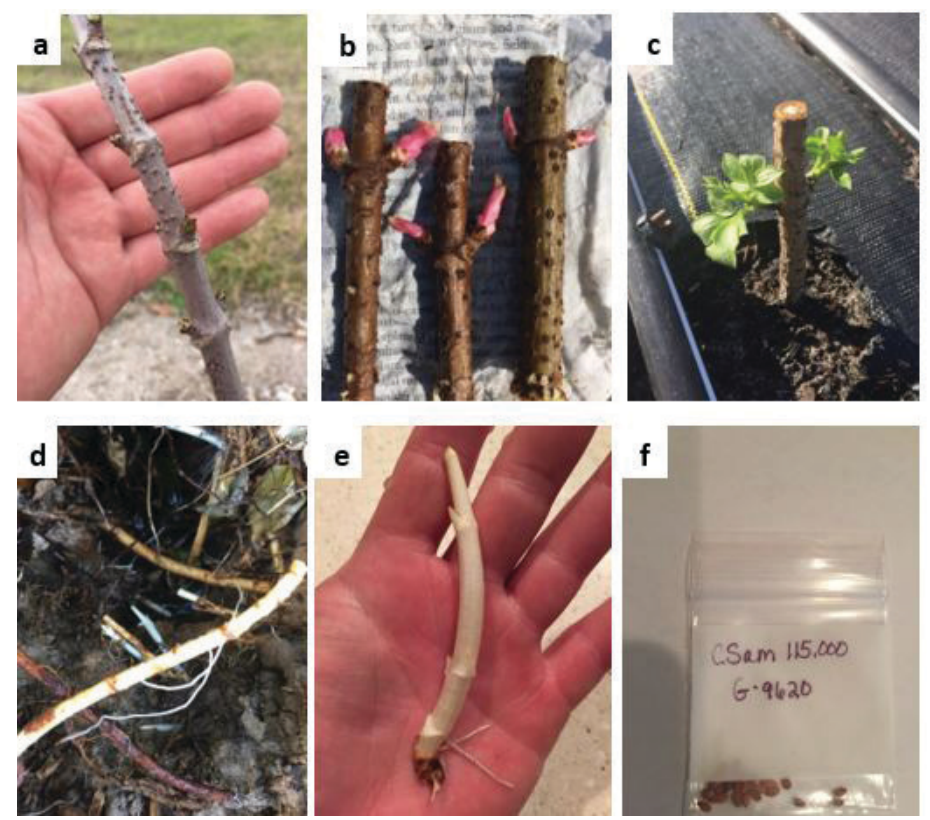

Figure 3. Propagation by hardwood cuttings $(\mathbf{a}, \mathbf{b}, \mathbf{c})$, stolon $(\mathbf{d}, \mathbf{e})$, and seed (f).

Credits: Hyldemoer + Co., Florida

Softwood cuttings are taken during the growing season and should be taken before flowering. Softwood cuttings must be potted in a sterile rooting medium to prevent decay. The rooting medium can be prepared by mixing peat moss and sand in equal amounts. Except for one pair of top leaves, all other leaves must be removed. The remaining steps are similar to that of propagation by hardwood cuttings but require more attention than hardwood cuttings to properly start. The rooted plants should be transplanted into 6-inch or larger pots and can be transplanted into the field the following season. Softwood cutting propagation of elderberry is seldom employed due to timing and the relative ease of propagation by hardwood cuttings.
Propagation by stolon section is an additional way to propagate elderberry. The main advantage of propagation by stolon section is that propagation material of this type can be taken over a long season annually and can be planted in a similarly long season either directly in ground or in pots. Stolon sections are planted horizontally at approximately one and a half to two inches deep, depending on soil type. The downside of propagation by stolon cuttings is the relative difficulty of digging or pulling sufficient material from the ground to gather significant volumes of planting material. The grower interested in a small planting may find propagation from stolon cuttings to be ideal because of the quality of the new canes produced initially as compared to top growth from hardwood cuttings. New canes emanating from the ground are typically more vigorous and faster to establish as compared to top growth from hardwood cuttings. Nursery production of elderberry starts propagated in this way is possible.

\section{Soil and Fertility Management}

Elderberry is well adapted to a wide range of soil types and fertility. However, the best yields for commercial cultivation can be obtained from well-drained, mildly acidic soils $(\mathrm{pH}$ 6.0-6.5). Florida soils are sandy and range from poorly drained to excessively drained. Therefore, if there are waterlogging issues after heavy rain, planting on raised beds is recommended. In the case of very quickly drained soils, the addition of organic matter in the form of properly aged compost becomes a requirement and is further discussed below. Soil amendment selection is critical for adjusting $\mathrm{pH}$ and must be able to be incorporated evenly to a depth of at least eight inches. Elderberry is relatively shallow rooted, and the $6 "-10$ " root zone is a critical depth for uptake of water and nutrients.

The potential for sustainable and/or organic cultivation of this hardy crop is one of its most important features. Organic fertilizers are considered less prone to loss due to off-gassing and leaching, both of which are commonly encountered in the use of conventional fertilizers. The ideal fertilizer program for elderberry is not well documented. Currently, there are no UF/IFAS fertilizer recommendation rates available for elderberry. Fertilization programs should be adjusted based on the results of leaf nutrient analysis. As a guide, nitrogen can be applied 4-8 weeks after planting at a rate of $10 \mathrm{lb}$ per 3,630 linear feet of row. This distance is most commonly used to describe an "orchard-acre" of growing area for Sambucus planted 2-3 feet apart in a row in rows spaced 12 feet on center. After the first season, test the soil and apply phosphorous and potassium at the recommended rate per 1,000 linear feet of cane fruit before 
the new season starts. Apply nitrogen at $60-80 \mathrm{lb} / \mathrm{acre}$ for mature, bearing elderberry until further trial results become available. Florida's sandy soil has severe nutrientleaching issues. Because of this, fertilizer should be applied in stages via fertigation when possible or via the proper use of slow-release fertilizers when fertigation is not practical.

To amend poor, sandy soils in Florida, compost is highly recommended. Mixing properly aged and high-quality compost into sandy soil will increase nutrient- and waterholding capacity and provide some slowly released nutrients. Compost also enhances the environment for many species of soil microbes. For example, mycorrhizae are fungi that form symbiotic relationships with plants by assisting in water and nutrient absorption while the plant provides carbohydrates in exchange. Elderberry greatly benefits from soil microbes because the relatively shallow root system can be augmented with networks of mycorrhizae or other soil microbes. The plant's very dense and fine feeder-root system creates an ideal environment for beneficial soil microbe communities. Without healthy soil conditions, elderberry cannot absorb all the micronutrients needed from the soil. Therefore, use of compost with microbial inoculants is helpful for the cultivation of elderberry in Florida's sandy soils.

\section{Planting and Irrigation}

Elderberry can be planted either in the spring or fall. Spring planting should be made after the last chance of frost to avoid damage to newly forming roots after planting. Fall plantings yield the fastest-establishing plants because the cool season encourages root development over vegetative growth. Issues with damage from grasshoppers as well as moles, gophers, and other soil-dwelling rodents may be encountered over the winter due to the relative dryness of the winter months in Florida and the need to provide irrigation throughout these dry periods. This moisture attracts overwintering pests due to the simple fact that a relative abundance of water is present from even brief irrigation.

If plants were held in pots before planting, any damaged or dead canes and 8 to 10 inches off the top of healthy canes should be pruned before planting. Use of a sealant for pruned canes is generally advisable at this stage, because the pithy core of elder canes is very attractive to a variety of wood-boring and nesting insects. Removing (pinching) flowering heads from the first-year plants also encourages the development of a good root system.
After planting, provide enough water to wet the entire root zone. Apply 1 to 2 inches of water to the root zone per week during dry periods, depending on soil type. Keeping roots from drying with frequent watering is important to establishment and production. The major uptake of water and nutrients in established plants occurs between the root zone depth of 6-10 inches in elderberry. The utilization of soil-moisture-sensing technology is highly recommended for determining proper irrigation scheduling. Above all else, elderberry is not tolerant to drought stress. Therefore, methods to keep soil moisture consistent are important for commercial cultivation. Drip irrigation using a $0.5-0.75$ inch plastic line with emitters spaced at $18-24$ inches is commonly used. More tightly spaced arrangements of emitters can be somewhat hard to find but may provide for a more consistent wetting pattern throughout the entire area of the row, especially if arranged in dual runs of drip line. Microsprinkler irrigation may be utilized depending on the grower's confidence in their ability to combat fungal disease pressure, but wetting of the ground-level leaves is counterproductive in most instances and should be avoided. If the plants are grown in bare-ground conditions, frequent watering is very important because Florida's sandy soil dries very quickly, and it is very hard to rewet if it dries completely. Covering rows with pine bark mulch or landscape fabric will help maintain soil moisture and discourage weed competition. Proper alleyway management is important for an elderberry orchard long-term.

The mature size of American elderberry is generally 10 to $12 \mathrm{ft}$ tall and wide (Figure 4). However, the utilization of primocane fruiting varieties along with coppicing techniques (see https://vergepermaculture.ca/2014/03/31/ coppicing/) could be used by elderberry growers in Florida to control plant size. Upon the end of the second to third growing season, the elderberry planting should be evaluated to ensure that colonization of new canes has been achieved in a radius out from the central plant crowns. This will display as "suckering" and demonstrates that the plants are mature enough to withstand heavy pruning close to ground level toward the end of winter while dormant.

Recommended spacing of elderberry for commercial cultivation ranges considerably by location and climate. Common recommendations range from $6 \mathrm{ft}$ between plants and $12 \mathrm{ft}$ between rows in more northerly climates, where coppicing of primocane bearing varieties is of little benefit due to the short growing season; to a very tight spacing of 2 or $3 \mathrm{ft}$ by 12 to $15 \mathrm{ft}$, with tighter row spacings possible for varieties with a more erect growth habit. Spacing can be adjusted to suit the farm's equipment or other orchard management considerations. Generally, a wider linear plant 
spacing encourages better growth with increased yields in the North, while in the South the higher air circulation provided by a wider, lateral row spacing may provide better disease control for a dense population in-row.

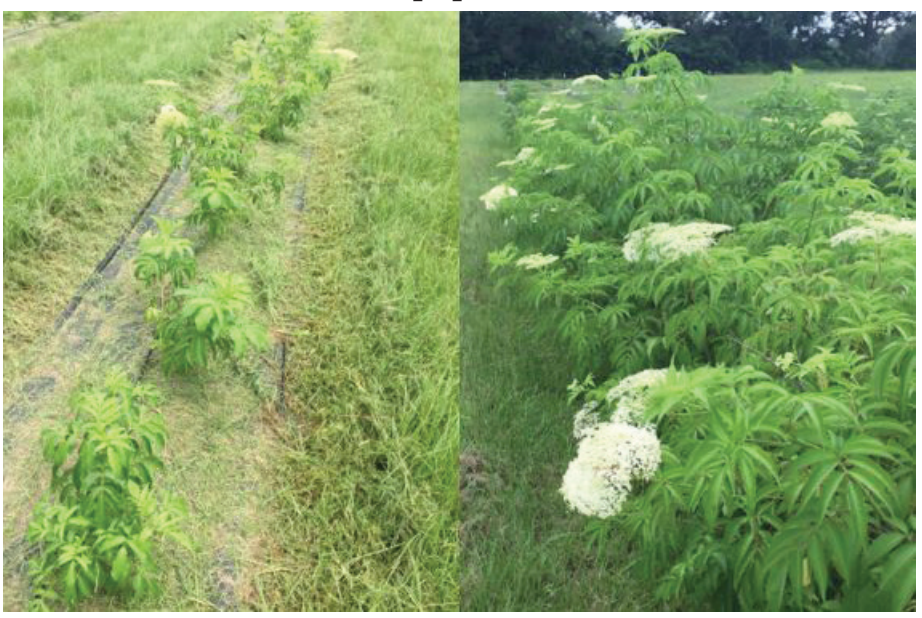

Figure 4. The same elderberry plants at 3-feet spacing in-row, Year 1 (left) vs Year 2 (right). Both photos taken in the month of June. Credits: Hyldemoer + Co., Florida

The pollination of elderberry flowers is not well studied, but many varieties are thought to be self-pollinated. Wind pollination is most commonly thought to be the norm throughout the Midwest and the northern United States. Insect-assisted pollination is also likely, especially in Florida, where the native phenotypes are frequented by pollinating insects to a higher degree than those varieties introduced from farther north. For a variety of reasons, including pollination, planting two or more cultivars together is considered desirable. The distance between the different cultivars should not be over $60 \mathrm{ft}$, and less than 20 $\mathrm{ft}$ is recommended. Alternating rows of different varieties could be employed, or mixing of varieties within a row could be done as lengths of a variety followed by another variety. Staggering of varieties in a pattern of $A, B, A, B$ within a row is not recommended, because differences in ripening periods between varieties can be notable, and this would hamper efficiency in harvest. This type of staggering will also present challenges to taking cuttings for further propagation because the stolons intermingle with each other in-row and become difficult to differentiate in the late, dormant season when hardwood cuttings are taken.

\section{Weed Control}

Weed control is important for successful elderberry cultivation because elderberry does not compete well with weeds during establishment. Limitations to the use of herbicides and mechanical weeding exist for the crop. Elderberry grows new shoots from crowns and roots every year. Because of this, herbicides must be used with extreme caution. In addition, the shallow root systems of elderberry are easily damaged by mechanical weeding. Therefore, the use of bark mulch and/or landscape fabric is invaluable to suppress weeds and to prevent the need for hand-weeding. Proper weed control also relies on appropriate row spacing and timely mowing, and these are critical components to successful establishment.

\section{Pruning Practices}

The pruning method for elderberry is determined based on the purpose and size of the farm. If elderberry is grown in the backyard or a small-scale orchard, where labor cost is not important, standard horticultural pruning can be performed to remove dead, damaged, or diseased stems and three-year-old branches or trunk. Pruning in the first two years is typically not needed. Pruning can be done during the dormant season preceding bud break.

For medium- to large-scale commercial cultivation, operational costs must be considered. Coppicing the canes near ground level reduces operational costs in commercial cultivation. Coppicing may reduce total yield, but it will result in larger fruiting cymes and more uniform fruit ripening across the orchard. Not all American elderberry varieties perform well with an annual coppicing routine, and none of the European cultivars of species $S$. nigra will bear on primocane (first-year) growth after coppicing. Some American varieties also range considerably in their ability to bear on new canes, which may be further influenced by the low chill-hour conditions of Florida winters. Therefore, further trialing of elderberry varieties, regardless of origin, needs to be conducted before specific recommendations are published. On-farm testing is underway in Florida to determine the best varieties and cultural practices, especially to determine the relative success of utilizing coppicing methods in Florida. In summary, coppicing has several advantages over standard horticultural pruning. First, it can reduce labor costs substantially because coppicing can be accomplished using equipment such as sickle-bar cutters. By coppicing, labor costs for harvest may also be reduced because there is a more concentrated fruit set with larger cymes produced, both of which reduce the harvest window and hand-moves during manual harvest. Coppicing also reduces risks from overwintering insect eggs, pests, and disease inoculum by removing all old stems from the orchard and destroying this material.

\section{Insect Pests and Disease}

Eriophyid mite (Phyllocoptes spp.), spider mite (Tetranychus urticae), stink bug (Halyomorpha halys), leaf-footed bug (Leptoglossus zonatus), armyworms (Mythimna spp.), spindle worm borer (Achatodes zeae), Japanese beetles 
(Popilla japonica), spotted-wing Drosophila (Drosophila suzukii), and other insect pests can be problematic for growing elderberry in Florida.
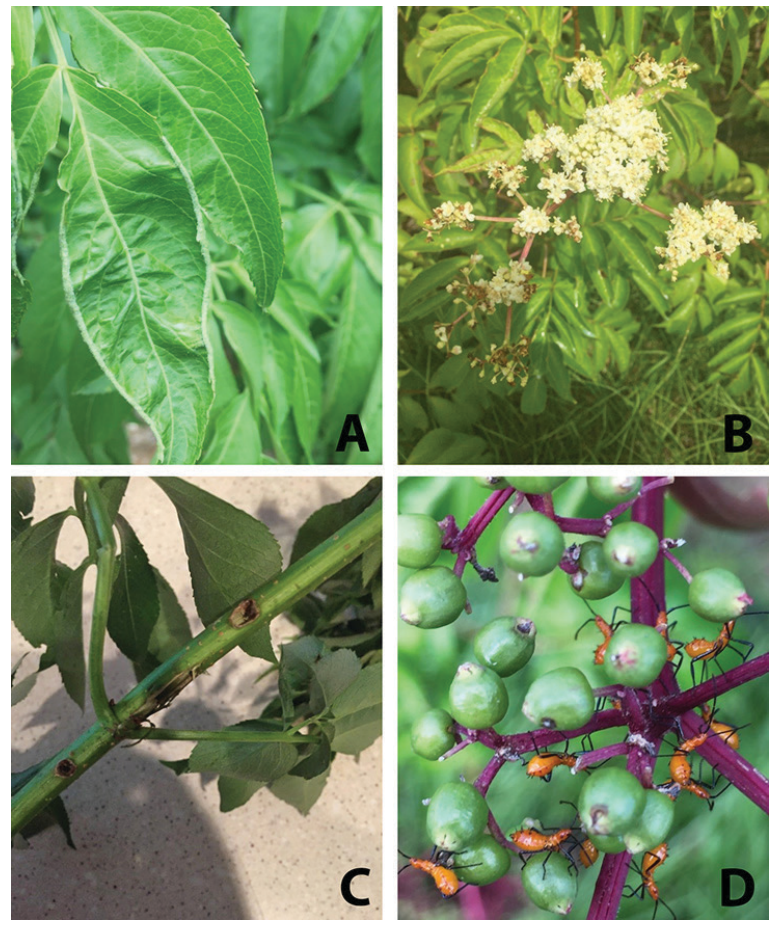

Figure 5. Early leaf infestation by Eriophyid mite (A), flower cyme with later Eriophyid mite damage (B), stem damaged by spindle worm borer (C), and leaf-footed bug nymphs on green berries (D).

Credits: Hyldemoer + Co., Florida

Spotted-wing Drosophila (Drosophila suzukii), or "SWD," is a major pest that causes economic loss in various fruit crops. It is an invasive fly pest found in Florida that infests unripe fruits; larvae cause feeding damage within the fruits. It also causes secondary damage by facilitating bacterial infections. Therefore, continuous monitoring and timely application of insecticides are important to prevent economic loss. If the grower encounters SWD in their crop, they should alert their local UF/IFAS Extension office. If the use of insecticides is restricted, physical barriers would be another option. Covering the developing, green berry cymes with a small mesh net (less than $1 \mathrm{~mm}$ openings) may protect fruit from damage by spotted-wing Drosophila, depending on orchard scale. The best option for control of SWD may be pheromone or scent-baited insect traps. Sulfur dust applied in early June offers good mite control. Weed control and mowing make the orchard less attractive to insects generally, and several traps are available to monitor insect pests as more is learned about the most damaging insect pests affecting Sambucus in Florida. The plant, new flowers, and ripe berries are attractive to deer, and the ripe berries are attractive to a number of bird species.
Elderberry is susceptible to fungal diseases such as Cercospora, elderberry rust (Puccinia sambuci), cankers, leaf spots, powdery mildews, and probably other, yet-to-beidentified bacterial and fungal diseases. Because of Florida's hot and humid climate and heavy rains during the growing season, the potential for high pressure from bacterial or fungal disease exists throughout the growing season. At least three sprays per year of neutral copper fungicide can reduce the disease impact. Nutrient deficiency often contributes to serious disease and pest outbreaks. Therefore, nutrient analysis of leaf tissue samples and correction of the deficient nutrients are needed until a stable fertilization program is developed.

\section{Harvest and Processing}

Both flowers and fruits can be harvested from Sambucus. Full production typically takes three to five years from planting. Harvesting can begin from the second year without impact on subsequent harvests, but first-year plants should have their flower buds pinched upon formation in order to stimulate root development. Native Florida elderberry starts to blossom in March or as early as February, and harvestable fruits are ripe as early as June. Fruit drop of the earliest berries is common and likely due to poor pollination, though more investigation is needed on this topic. Phenotypes from farther north begin to flower in May or June and fruit ripens from July through August. Coppicing will generally delay fruit formation and ripening. The harvest period of mixed shoots following standard pruning is about four to five weeks or longer, whereas harvest of fruit on new shoots after coppicing is about three to four weeks.

Some varieties being trialed in Florida show promise for a secondary, condensed winter harvest season, while the native Florida types may be harvested over a long season because they are highly indeterminate. This indeterminate characteristic could be a positive attribute for smaller-scale growers, but it would typically be a hindrance to efficiency in larger-scale operations because a grower would need to select and harvest judiciously and frequently over a very long season. An additional consideration for growing native Florida phenotypes is that they should only be grown for their fruit. Compared to other varieties from farther north, native Florida phenotypes lack culinary value of the flowers because they do not have the desirable aroma and strength of fragrance found in other varieties. If the reader believes they have a native Florida specimen displaying superior flower fragrance and strength, they are encouraged to reach out to the authors. 
The flower cyme of commercially grown varieties can be harvested when all the flower buds are open. Optimum fragrance is usually found in the morning hours on less humid days. Ripening of elderberry fruit is uneven between cymes. Therefore, individual cymes should be harvested by hand as the berries ripen to a uniformly reddish-black to bluish-black color, depending on variety, or at the observation of a slight wrinkling of the fruit skin (Figure 6). Care must be taken not to wait too long to harvest the cyme, or the berries will begin to drop as they become overripe. The best method to determine the proper stage of fruit maturity is to utilize a refractometer to test Brix in the field. Ripe elderberry typically tests at 9-11 degrees Brix, but the grower will need to determine the optimal Brix for given varieties on their farm and use that experience going forward.
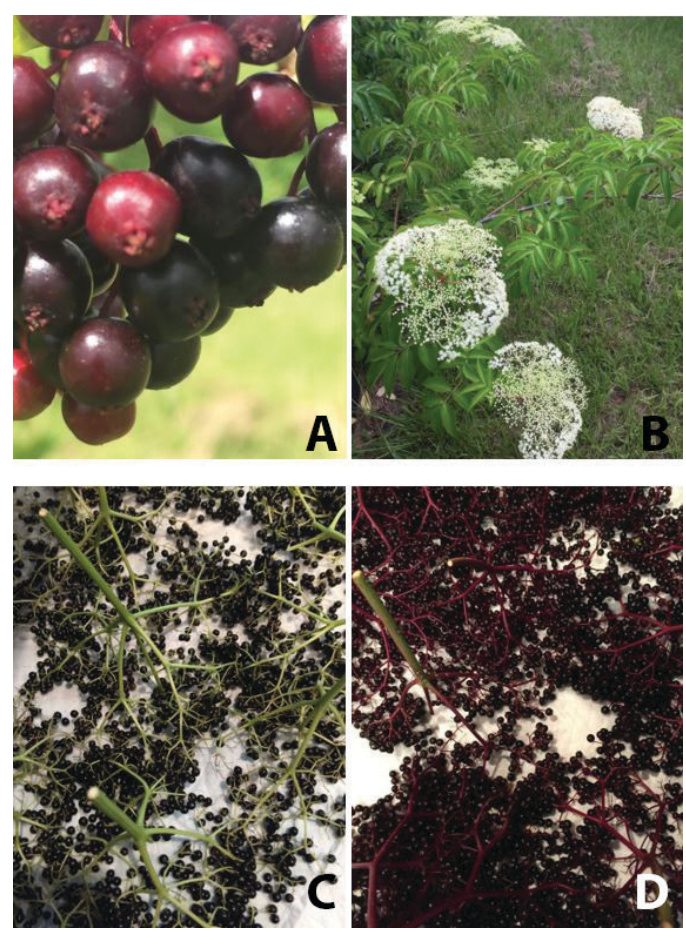

Figure 6. Ripening elderberry about 1 week prior to harvest (A) and nearly ready elderflower (B); harvested cymes of a native-Florida phenotype (C) vs. S. canadensis (D).

Credits: Hyldemoer + Co., Florida

Elderberry fruit are easily damaged by harvesting. To prevent this, whole cymes are cut with the fruit attached, and the fruit are removed by specialized destemming equipment. The expected yield of mature American Sambucus ranges from two to three tons per acre with proper growing conditions and management.

The harvested fruit are very perishable, and quality can be lost within a matter of hours after harvest in the Florida heat. Therefore, fruit must be quickly processed following harvest or refrigerated at $32^{\circ} \mathrm{F}-40^{\circ} \mathrm{F}$ for temporary storage prior to processing. Processing of fresh fruit includes freezing $\left(-4^{\circ} \mathrm{F}\right)$, pressing for juice, or dehydration for longerterm storage. Depending on the next processing step, fruit also can be stored after dehydration in low-humidity facilities for a length of time.

\section{Toxicity}

Sambucus has been noted for possible toxicity concerns in the United States, and confusion on the specifics has led to general statements on the degree of this concern. For example, a 1983 incident in California was reported by the CDC describing illness experienced by 11 individuals, including a single hospitalization, and attributed to the improper handling of wild Sambucus plants referred to as S. mexicana: "Bunches of berries were crushed with their leaves and branches in a stainless-steel press. Apple juice, water, and sugar were added, and the mixture was stored overnight. The drink was served the next day in a stainlesssteel pot to the group of 25 persons" (CDC 1984).

While no other documented instance of toxicity is readily available, this incident illustrates that plant materials of Sambucus other than ripe fruit and flowers should not be ingested. The leaves, stems, canes, roots, unripe berries, and possibly the seeds of Sambucus contain compounds known as cyanogenic glucosides. The specific compound of greatest concern is often referred to as sambunigrin. Ingestion of plant material other than ripe fruit and flowers can cause release of cyanide into the body, correlating to the amount of these materials consumed.

Additionally, ripening of the fruit across the orchard, as well as within the singular cyme, is not uniform in the case of many varieties. Generally, the larger the individual cyme, the greater the disparity in the ripeness of the fruit across the cyme. Because of this, proper sorting of fruit is essential to remove green and underripe berries as well as the peduncles (the fine stems attached to the berry). The grower should keep in mind that the berry is formed to accomplish the dispersal of viable seed by birds, and the viability of the seed coincides with the ripeness of the berry.

Instructions on proper processing of the fruit prior to ingestion often recommend heating the pulp or juice, which completely breaks down the cyanogenic glucosides. Overheating is unnecessary and results in breakdown of nutritious compounds contained in the fruit. Alcoholic fermentation is also often cited as a method of breaking down the undesirable compounds. The newest research on the topic of cyanide-producing compounds in American Sambucus further points to an overgeneralization of toxicity 
concerns of ripe fruit: "Detected levels pose no threat to American Elderberry consumers. Excluding stems, green berries and leaves in juice preparation is recommended" (Thomas 2019).

It is necessary for Sambucus growers to become familiar with the proper handling of the fruit in order to safeguard the consumer, most importantly, and to protect the future of this crop in Florida. Some buyers of elderberry require confirmation of the identity of varieties grown to ensure that toxicity concerns are mitigated, which is further reason to avoid growing selections taken from the wild in Florida at the commercial scale until a given phenotype is properly evaluated. Sambucus may not be viable as a u-pick crop in the short term. Proper handling requirements of Sambucus, taken as a whole, necessitate an approach to marketing the crop in a manner that eliminates any toxicity concern for the consumer.

\section{Conclusions}

Sambucus is growing in demand and presents interested growers in Florida with a unique opportunity. The crop is well situated for development in Florida's climate and is suitable for cultivation on marginal lands, including small holdings and land with terrain that is unsuitable for crops grown at scales necessitating mechanization of harvest and planting. Proper irrigation management and a mindful approach to weed, pest, and disease control are required, but Sambucus is a comparatively vigorous and hardy crop as compared to many fruits commonly grown in Florida. The successful establishment of the crop will benefit from further trialing of variety selections and research on the best cultivation practices. Opportunities for future research on postharvest handling techniques, proper fertilizer protocols, disease management, and market channels are all available.

\section{References}

Applequist, W. L. 2015. "A Brief Review of Recent Controversies in the Taxonomy and Nomenclature of Sambucus nigra sensu lato." Acta Hort. 1061:25-64.

Brobst, J. (editor). 2013. Elderberry: An Herb Society of America Essential Guide. Kirtland, OH: The Herb Society of America.

Byers, P. 2015. Elderberry Propagation. University of Missouri. http://kerrcenter.com/wp-content/uploads/2015/10/ ElderberryPropagation.pdf
Charlebois, D., P. L. Byers, C. E. Finn, and A. L. Thomas. 2010. Elderberry: Botany, Horticulture, Potential. Horticultural Reviews 37.

Gilman, E. F., and D. G. Watson. 2014. Sambucus mexicana: Mexican Elder. ENH-738. Gainesville: University of Florida Institute of Food and Agricultural Sciences. https://edis.ifas. ufl.edu/st580.

Grebow, J., and S. Krawiec. 2020. "Ingredients to Watch: The 2020 List." Nutritional Outlook vol. 23, 1.

Henderson, J. 2017. "The Business of Organic Elderberry.” Eco Farming Daily. https:// www.ecofarmingdaily.com/grow-crops/growfruits-vegetables/fruit-and-vegetable-crops/ the-business-of-organic-elderberry/

Kaiser, C., and M. Ernst. 2018. Elderberry. CCD-CP-5. Lexington, KY: University of Kentucky.

Mudge, E., W. L. Applequist, J. Finley, P. Lister, A. K. Townesmith, K. M. Walker, and P. N. Brown. 2016. "Variation of Select Flavonols and Chlorogenic Acid Content of Elderberry Collected throughout the Eastern United States." Journal of Food Composition and Analysis 47:52-59.

Ozgen, M., J. Scheerens, R. Reese, and R. Miller. 2010. "Total Phenolic, Anthocyanin Contents and Antioxidant Capacity of Selected Elderberry (Sambucus canadensis L.) Accessions." Pharmacogn Mag. 6 (23): 198-203.

Roschek, B., R. C. Fink, M. D. McMichael, D. Li, and R. S. Alberte. 2009. "Elderberry Flavonoids Bind to and Prevent H1N1 Infection In Vitro." Phytochemistry 70:1255-1261.

"Sambucus nigra ssp. canadensis." 2018. Plant Database. Ladybird Johnson Wildflower Center. University of Texas at Austin. https://www.wildflower.org/plants/result. php?id_plant=sanic4. Accessed April 24, 2020.

Stevens, M. 2001. Plant Guide for Common Elderberry. Baton Rouge, LA: National Plant Data Center, USDA-NRCS.

Thomas, A. L. 2019. "Elderberry Flower Production and Cyanide Concern." University of Missouri Division of Plant Sciences Southwest Research Center Mt. Vernon, MO. https://www.greatplainsgrowersconference.org/uploads/2/9/1/4/29140369/elderberry_cyanide_st._joe_january_2019.pdf 
Wilson, R., G. Nickerson, D. Fried, J. Hayden, G. Masé, T. Hardie, J. Faulkner, M. Sisock, T. L. Jackson, D. T. Handley, and M. L. Peronto. 2016. Growing Elderberries: A Production Manual and Enterprise Viability Guide for Vermont and the Northeast. Burlington, VT: University of Vermont.

Zakay-Rones, Z., E. Thom, T. Wollan, and J. Wadstein. 2004. "Randomized Study of the Efficacy and Safety of Oral Elderberry Extract in the Treatment of Influenza A and B Virus Infections." The Journal of International Medical Research 32:132-140. 